
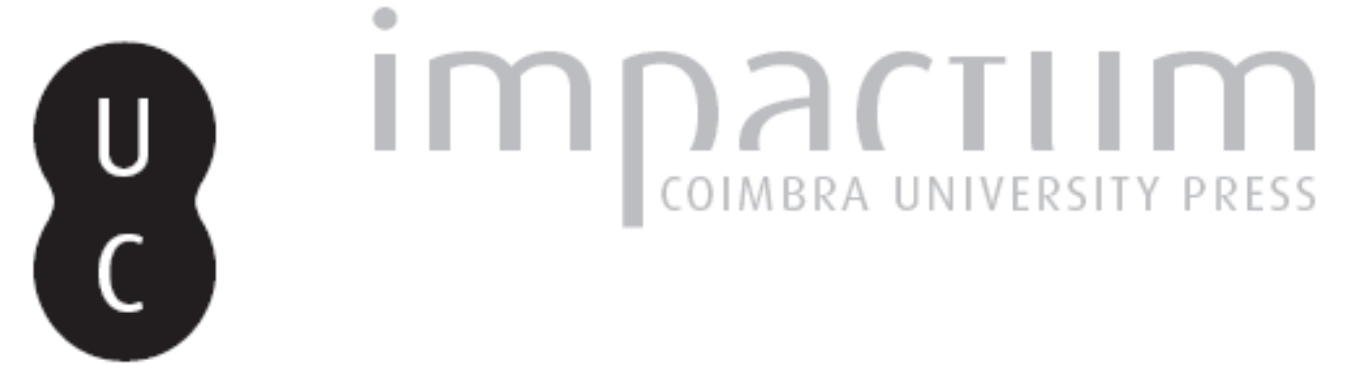

\title{
[Recensão a] Giochi di specchi. Modelli, tradizioni, contaminazioni e dinamiche interculturali nei e tra i paesi di lingua portoghese
}

Autor(es): $\quad$ Simões, Manuel G.

Publicado por: Imprensa da Universidade de Coimbra

URL persistente:

URI:http://hdl.handle.net/10316.2/44986

DOI:

DOI:https://doi.org/10.14195/0870-8584_12_22

Accessed : $\quad$ 26-Apr-2023 11:35:53

A navegação consulta e descarregamento dos títulos inseridos nas Bibliotecas Digitais UC Digitalis, UC Pombalina e UC Impactum, pressupõem a aceitação plena e sem reservas dos Termos e Condições de Uso destas Bibliotecas Digitais, disponíveis em https://digitalis.uc.pt/pt-pt/termos.

Conforme exposto nos referidos Termos e Condições de Uso, o descarregamento de títulos de acesso restrito requer uma licença válida de autorização devendo o utilizador aceder ao(s) documento(s) a partir de um endereço de IP da instituição detentora da supramencionada licença.

Ao utilizador é apenas permitido o descarregamento para uso pessoal, pelo que o emprego do(s) título(s) descarregado(s) para outro fim, designadamente comercial, carece de autorização do respetivo autor ou editor da obra.

Na medida em que todas as obras da UC Digitalis se encontram protegidas pelo Código do Direito de Autor e Direitos Conexos e demais legislação aplicável, toda a cópia, parcial ou total, deste documento, nos casos em que é legalmente admitida, deverá conter ou fazer-se acompanhar por este aviso.

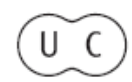




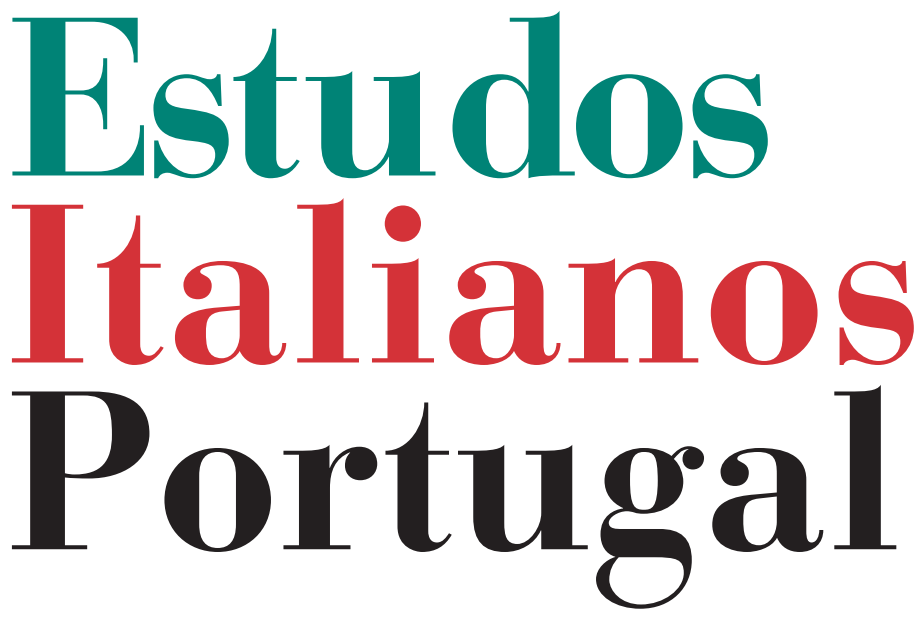

Instituto

Italiano

de Cultura

de Lisboa

Nova Série

No 12

2017 
Giochi di specchi. Modelli, tradizioni, contaminazioni e dinamiche interculturali nei e tra $i$ paesi di lingua portoghese, a cura di Monica Lupetti e Valeria Tocco con Valeria Carta, Sofia Ferreira Andrade, Mauro La Mancusa, Giuliana Paolillo, Pisa, Edizioni ETS, 2016, 635 pp.

O presente volume reúne as comunicações apresentadas ao II Congresso AISPEB (Associazione Italiana di Studi Portoghesi e Brasiliani), realizado em Outubro de 2014, e fornece obviamente um mosaico variegado de estudos que se inserem no complexo mundo de língua portuguesa, traçando "a grandi linee, alcune mappe di peregrinazioni letterarie e linguistiche, e i frutti di tali peregrinazioni nel tempo e nello spazio", como referem Monica Lupetti e Valeria Tocco na apresentação exordial (p. 11). Divide-se em seis estimulantes secções e um apêndice, este dando conta, numa espécie de memória, de alguns eventos que serviram de contorno ao congresso e contemplando a fotografia, o cinema, a literatura e o teatro, modos significativos de complementar os discursos sobre as culturas lusófonas. A primeira secção, intitulada "Tra Italia e mondi di lingua portoghese", compreende oito comunicações, das quais se deve destacar o texto de Rita Marnoto, em que a conhecida estudiosa analisa as "relaçôes culturais entre Portugal e a Itália”, considerando-as na sua excentralidade e policentralidade. Já autora de diversos estudos sobre o tema (basta atentar na bibliografia), Rita Marnoto revisita os "grandes vectores" que influíram no relacionamento entre as duas culturas, apontando apenas, como não podia deixar de ser, as suas "linhas estruturantes". Este texto está directamente ligado à breve mas essencial comunicação de Davide Conrieri, o qual sublinha, numa 
espécie de recensão, o perfil metódico e as observações específicas, anotando, por seu lado, algumas variaçōes ao diálogo entre a Itália e Portugal.

Neste primeiro sector das comunicações ao congresso, deve referir-se o texto oportuno de Mariagrazia Russo, o qual, tratando do "presente e o futuro da língua portuguesa na escola italiana", desenvolve o programa para a formação de professores de português e as etapas pedagógicas do curso de "Lingua e civiltà: portoghese"; e também o texto de Vera Lúcia de Oliveira, na esteira de uma tradição de estudos sobre a presença do Véneto no Brasil (lembre-se o caso paradigmático de José Clemente Pozenato), analisando aqui a poesia de Eduardo Dall'Alba vista como documento sociológico e antropológico, âmbito que se pode aplicar também à comunicação de Benedito Antunes relativamente ao falar dos emigrantes italianos na região de São Paulo em textos de Juó Bananére. É um aspecto semelhante ao do chamado "talian" de Naneto Pipeta, de base idiomática véneta, nas regiōes de Rio Grande do Sul e de Santa Catarina, ambos já objecto de estudo num brilhante ensaio da ilustre lusitanista Giulia Lanciani.

À segunda secção, "Modernismi", são dedicadas seis comunicaçôes, quatro das quais sobre aspectos do universo pessoano, contemplando as outras duas a obra em prosa de Almada Negreiros. Pelo seu interesse específico, saliente-se o trabalho de Silvano Peloso, "Fernando Pessoa e la quarta dimensione dell'arte e della mente", onde o autor estuda a poética pessoana no contexto da tradição hermética, o que conduz a investigação para uma síntese em que se observa a reunião da inteligência material e da espiritual (p. 114); e também a comunicação de Elisa Alberani sobre "o contributo italiano para a construção do 'mito' literário pessoano", na qual se analisa a função das traduçôes, da crítica (e lembro aqui o primeiro volume crítico italiano, L'alibi infinito, de Ettore Finazzi-Agrò) e da intertextualidade na narrativa italiana, de que são exemplo os romances de Antonio Tabucchi. Já sobre a prosa de Almada Negreiros, integrando-a na chamada literatura do "nonsense", são pertinentes os estudos de Mauro La Mancusa (sobre $A$ Engomadeira) e de Valeria Tocco ("K4 e la geometria del nonsense"), este último acentuando os princípios desconstrutivos inspirados na "revelação de Marinetti”.

Segue-se a terceira secção ("Dialoghi intra e translusofoni"), a mais extensa nas suas quinze comunicaçōes, até porque abrange um cam- 
po alargado de temas e problemas, cuja proposta pretendia justamente o confronto predominante entre as várias culturas do mundo lusófono. $\mathrm{Na}$ variedade e no mérito indiscutível dos vários projectos, são de relevar: a comunicação de Ada Milani, que estuda o impacto da teoria luso-tropicalista de Gilberto Freyre e seu aproveitamento pelo Estado Novo, analisando aqui as críticas explícitas dos conhecidos intelectuais africanos, Mário Pinto de Andrade e Amílcar Cabral; a exegese conduzida por Roberto Francavilla ao conto de Herberto Hélder, "Teorema" (Os Passos em Volta), da qual o estudioso parte para observar como mais uma reescrita de um topos medieval (o mito de Inês de Castro) estabelece o "diálogo com a história cultural" (p. 323); e o bem fundamentado texto de Giorgia Casara, que estuda as primeiras manifestaçōes da "crítica literária moderna” em Portugal, partindo da reflexão inédita de $\mathrm{Al}$ meida Garrett e de Alexandre Herculano para se deter essencialmente na figura de Lopes de Mendonça, que Antero de Quental viria a reconhecer como precursor e mestre da moderna crítica literária em Portugal, antecipador, portanto, dos fundamentos da polémica conhecida como a "Questão Coimbrâ". A quarta e quinta secçōes, respectivamente "Transdisciplinarità" e
"Traduzione", são as mais breves no conjunto do volume, com quatro comunicações cada uma. Neste sector de estudos há que referir o artigo de Rosa Maria Sequeira, "Jogo de espelhos no donjuanismo português”, até porque, a julgar pelas referências, este é o seu sétimo trabalho dedicado ao mito de Don Juan na literatura portuguesa, que, como se sabe, foi introduzido em Portugal pelos poetas da "geração de 70", talvez com Teófilo Braga, como antecipação do decadentismo do final do século. Apesar da ampla bibliografia, esta comunicação poderia ter beneficiado com os estudos de Vanessa Castagna, de Gianluca Miraglia e até do autor destas linhas, susceptíveis de completarem alguns aspectos e a própria pesquisa de obras contemporâneas. E no capítulo dedicado à tradução, especial relevo merece o breve mas essencial artigo de Andrea Ragusa sobre a tradução italiana de Frisos e de Saltimbancos, de Almada Negreiros, tarefa árdua levada recentemente a cabo por um grupo de tradutores, do qual ele próprio fazia parte.

Por último, a sexta secção ("Lingua, Lingue, Linguistica”) engloba onze comunicaçóes, das quais é lícito destacar o "diálogo" estabelecido entre Marcos Bagno ("Por que uma gramática brasileira?") e o comentário de Roberto Muli- 
nacci ("Uma gramática brasileira ... e por que não?"), abordando, portanto, uma questão controversa que se agudizou com o chamado acordo ortográfico (AO90). Marcos Bagno é, desde o início, sumamente explícito ao referir que o debate proposto "tem como base o argumento de que português brasileiro e português europeu são duas línguas diferentes" (p. 477). Pessoalmente estou de acordo quanto à definição de "lusofonia" como projecto político-ideológico e também subscrevo que "não existe ciência neutra” (p. 487). Mas após o discurso bem elaborado sobre algumas características que contradistinguem a gramática do $\mathrm{PB}$, envolvendo, portanto, questôes linguísticas, confesso a minha surpresa quando, a concluir, o estudioso faz depender a diferenciação sobretudo da decisão política. A "recensão" de Roberto Mulinacci parece-me mais equilibrada na medida em que, embora concorde com a tese política no "eventual reconhecimento do português brasileiro como língua plena e autônoma” (p. 491), não deixa de se apoiar em muita literatura científica para defender "a existência in re de uma gramática brasileira” (p. 490).

Por tudo quanto fica escrito, creio que emerge uma opinião de grande apreço pela quantidade e indubitá- vel qualidade das propostas, muito se ficando a dever à organização do congresso e à arrumação dos materiais, o que faz deste volume um "manual" de consulta obrigatória para futuras investigações na área dos estudos sobre as várias culturas de língua portuguesa. MANuel G. SIMŌES

Paola Nestola, San Giuseppe da Copertino: dall'estrema Puglia al Portogallo (secc. XVII-XIX), Lecce, Edizioni Grifo, 2016, 286 pp.

A autora deste livro é investigadora do Centro de História da Sociedade e da Cultura (CHSC) da Universidade de Coimbra e tem-se dedicado, nos últimos anos, com grande proficiência, a estudos de História Religiosa. Este volume, editado com o apoio do CHSC, é composto por textos inéditos e artigos recentes publicados em revistas científicas e em atas de congressos. O livro conta com uma esclarecedora introdução e seis capítulos: I Virtutem ad emulandum: la castità di fra' Giuseppe tra pratica sacramentale e "sollecitatio ad turpia"; II - La Santità al femminile: San Giuseppe da Copertino tra culto popolare e culto elitario; III - S. Giuseppe da Copertino, un patronato toponimico emblematico: 